\title{
The Indirect Approach: Towards Non-Dominating Dementia
}

\section{Care}

\author{
Matilda Carter $^{1}$ D
}

Accepted: 9 November 2021 / Published online: 25 November 2021

(c) The Author(s) 2021

\begin{abstract}
Carers often interfere with the choices of people living with dementia. On neorepublican and (most) relational egalitarian views, interference can be justified if it tracks a person's interests: if it does not lead to a relationship of domination. However, the kind of environment-shaping interventions carers often pursue would be considered infantilising or objectionably paternalistic in other cases. In this paper, I defend this indirect approach and argue that it offers the best prospects of dementia care without domination.
\end{abstract}

Keywords Dementia $\cdot$ Domination $\cdot$ Relational egalitarianism $\cdot$ Social justice

\section{Introduction}

In recent years relational egalitarianism has come to occupy an increasingly influential position in contemporary political philosophy. Broadly speaking, scholars who adhere to this school of thought believe that social justice is achieved when paradigm inegalitarian relationships, such as oppression and stigma, are eliminated from society. For most if not all relational egalitarians (Nath, 2020), this also entails a prohibition on domination, understood in Phillip Pettit's terms: the capacity of powerful agents to interfere in the choices of others (i) without tracking their interests and (ii) with impunity (2006, pp. 275-276).

However successful this approach may be in other areas, it faces a number of challenges from philosophers concerned with the care of dependants. Assuming that recipients of care are also entitled to be related to as equals, this view of justice would require them to be liberated from domination. Yet according to a number of theorists, including Marilyn Friedman (2008, p. 254), Anca Gheaus (2020) and Eva Feder Kittay (1999, pp. 30-31), the capacity to arbitrarily interfere may be a necessary component of at least some caring relationships. If they are right, then

Matilda Carter

Matilda.2.carter@kcl.ac.uk

$1 \quad$ King's College London, London, UK 
relational egalitarians must either deny that recipients of care are entitled to liberation from domination, threatening their egalitarian credentials, or abandon Pettit's definition of domination.

A full exploration of every kind of dependency relationship is, naturally, beyond the scope of a single paper. In this paper, rather, I focus on one: the relationship between a carer and a person living with dementia. As I shall argue, it is possible for such a relationship to be non-dominating. Thus, relational egalitarians can avoid excluding them from the scope of justice and maintain the centrality of domination to their view.

The argument proceeds as follows. In Sect. 1, I elaborate on the concept of care in order to develop a working definition of dementia care. In Sect. 2, I set out the indirect-first approach to dementia care, demonstrating its ability to prevent carer domination. Finally, I consider a series of objections to the monitoring necessary to prevent or punish instances of non-interest tracking interference but give reasons for thinking that these are less stark than they appear.

\section{What is Dementia Care?}

Before considering different approaches to it, it is necessary to gain some clarity on what dementia care actually is. Care, after all, is a notoriously slippery concept; Virginia Held highlights its polysemous nature by observing that among many other senses: we tell people to take care when they leave, we sometimes talk about caring for particular kinds of music and we often speak of caring about political issues (2006, p. 30).

Of course, it is possible to care for someone living with dementia in many of these senses, but they may not always accompany the provision of dementia care. After all, it seems unlikely that abusive or neglectful carers care about the people living with dementia they work with, but it still seems more accurate to say that they are providing care badly than that they are not providing it at all. There is, thus, a distinction between care as an activity and care as a value, practice or feeling. The indirect-first approach, as I defend it here, concerns only the former.

Even when specified in this way, however, the boundaries of care are fuzzy and difficult to define. Indeed, many definitions are overly broad or otherwise implausible. Joan Tronto, for instance, defines caring as, 'everything we do to maintain, continue and develop our world so that we can live in it as well as possible' (1993, p. 103). Admittedly, this covers most if not all of the activities involved in dementia care, but it also includes activities that have little to do with it.

The atomic bombs dropped by the US military on Japan, at least on one common reading of history, hastened the end of the Second World War, helping to maintain and continue the world by rescuing it from a state of war between powerful states, and helping to develop it by ensuring the defeat of fascism, ensuring that we would live in it as well as possible. Yet, it seems absurd to think that devastatingly violent acts of warfare are caring activities, as Tronto's definition seems to imply.

Diemut Bubeck offers a more precise definition, where caring refers to the meeting of the needs of one person by another person, where face-to-face 
interaction between carer and cared-for is a crucial element of the overall activity and where the need is of such a nature that it cannot possibly be met by the person in need herself' (1995, p. 129). However, while these conditions are specific enough to avoid pulling in activities that obviously have little to do with care, the definition is still too expansive. Rescuing a drowning person who cannot swim involves meeting a need for survival, via face-to-face interaction, which the person cannot meet for themselves. Likewise, killing the captor of a hostage may meet their need to be rescued that they cannot meet themselves, via face-to-face interaction. Of course, both of these acts may be motivated by a desire to care, but neither has much to do with care as an activity.

Now, it may be objected that face-to-face interaction is not a crucial element of these activities, on a more stringent definition of that term, so the definition does not include them. However, this only serves to highlight that the conditions are problematically restrictive too. After all, a parent does not need to interact with their child face-to-face to prepare them a packed lunch, clean their clothes or keep their environment safe. Excluding these acts from the definition of care as an activity seems highly counterintuitive, but this is precisely what Bubeck's conditions do.

A more promising attempt at defining care as an activity comes from Eva Feder Kittay, who uses the term 'dependency work' to describe activities engaged in by workers who direct their 'energies and attention' towards a 'charge' who, without a dependency worker 'would be bereft of life-sustaining resources' (1999, pp. 30-31). As this definition focuses on the roles involved in care as an activity, rather than the nature of the acts themselves, many of the above examples fall on the right side of the line. After all, there is no dependency worker in the dropping of atomic bombs, but there is in the making of packed lunches.

However, by not specifying the type of acts which are included, the definition may render anything a dependency worker does with the charge in mind an act of care. This might include buying a bus ticket to get to work, setting an alarm to make sure that they get up on time or giving themselves time to recoup to ensure they can carry out their duties well. To be clear, all of these acts may be caring, in the sense that they help the dependency worker to carry out care as an activity well, but it would be counterintuitive to think of them as acts of care in themselves.

Perhaps this is an uncharitable interpretation, and Kittay should be read only as referring to those activities which directly ensure the charge is not bereft of lifesustaining resources. If we read her this way, however, the definition becomes too exclusionary. Activities like playing a game with a person living with dementia or accompanying them for a walk can contribute to emotional and physical wellbeing, but they do not directly ensure access to life-sustaining resources. Yet, especially in the context of high levels of dependency, it is surely intuitive to count them as caring activities.

Each of these definitions of care is problematic, yet all contain vital insights that can be used to build a working definition of care as an activity. Firstly, as Kittay rightly notes, these activities are performed by specified agents in service of others, taking place in the context of a caring relationship. As well as excluding the problematic examples noted above, requiring a designated carer and charge also helps to 
exclude social practices such as welfare payments or policing from the definition of care as an activity.

Secondly, these activities need to be directed towards the charge, rather than being tangentially related to them. This helps to separate activities that may bear on whether or not the dependency worker will perform care well, from the activity itself. Kittay's implied 'life-sustaining resources' condition, however, is too narrow, so it ought to be replaced with a more general condition that these activities are provided because without them a number of vital needs, including nutrition, emotional wellbeing and health, would not be met.

Thirdly, contra both Kittay and Bubeck, it need not be the case that a person would be entirely bereft of the necessary resources to meet their needs or is incapable of meeting them themselves. Though this helpfully excludes services provided for other reasons, such as Bubeck's example of a person cooking a meal for their non-disabled spouse (1995, p. 129), it also excludes several activities involved in paradigm care relationships.

Consider, for instance, a disabled person who can meet their own needs by themselves, but only with the most extraordinary effort. If that person chooses to hire a carer so that they can reduce the strain on their energy, it seems obvious that the activities that worker provides ought to be understood as care. Likewise, a person may be capable of meeting each of their vital needs individually but may struggle to meet all of them, whether due to limited energy or a difficulty co-ordinating their actions. Given this, it would be better to invoke Tronto's language; the charge may either be unable to meet the need on their own or can only do so in a way that severely threatens their ability to live in the world as well as possible. ${ }^{1}$

These three conditions provide a clear, working definition of care as an activity, which can be used to clarify the bounds of dementia care. Where a person living with dementia is situated as a charge in a relationship with a dependency worker, who directs their energies towards them to meet vital needs they either cannot meet alone or can only do so with extraordinary effort, they are in receipt of dementia care. As they are dependent on this relationship to meet their vital needs, carers are invested with a significant amount of power. Where carers are given license to use this power without due regard to the interests of those they are caring for, those relationships become dominating, on the standard neorepublican account. The indirectfirst approach, as I will set out below, is intended to prevent this relationship from taking on this inegalitarian character.

\footnotetext{
${ }^{1}$ I say 'severely' here to differentiate between carers and workers such as butlers or housekeepers. While the latter certainly improve their client's chances of living in the world as well as possible, they are not in place to prevent a serious threat and are, thus, not care workers. Though I will not specify a threshold of severity here, it suffices to say that anybody who can only meet their needs in ways that threaten their dignity is in need of care.
} 


\section{The Indirect-First Approach}

A non-dominating dementia care relationship is one in which a carer's interventions robustly track the interests of the person they are caring for. In previous work I have defended the view that people living with dementia, despite their cognitive impairments, are capable of generating authentic values, from which interests can be derived (Author, date reference to author's own work redacted). Thus, when I refer to the interests of people living with dementia here, I am invoking those who are, in Pettit's terms 'avowal ready', through their relationship with the person's authentic values, rather than seeking to determine them from an objective standpoint (2006, pp. 275-276).

No doubt, this will often be tailored to the specific lives of individuals; bringing your dog to work with you might track the interests of one person you are caring for, but if another is allergic to or petrified of dogs, it will clearly not. Nevertheless, given the common symptoms of dementia, it ought to be possible to establish a general picture of the kind of interventions which reliably track their interests.

In this section, I argue that direct interventions to meet vital needs ought to be avoided, where possible, because they decrease the ability of a person living with dementia to develop and express their wider interests, hasten the decline of their capacities and decrease the control they have over their care relationship. No doubt some will eventually require extensive direct intervention to meet their vital needs, but this does not negate the argument I will make here; all people living with dementia, in so far as they are capable of it, have an interest in being allowed or assisted to meet their own needs, so care which frustrates this does not track their interests.

\section{The Case Against Direct Intervention}

Consider the following scenario:

During a visit to his brother Barry's house, Luke notices that he has not shaved, is wearing dirty clothes and that there is expired food in his fridge. Most alarmingly, he also appears to have left his gas stove on. While trying to discuss this with him, Barry is uncharacteristically evasive and defensive. After some persistence, Barry relays to Luke that he is fine, and he is just struggling to keep on top of the housework as his job has become very tiresome recently. Luke becomes very concerned at this, as Barry has been retired from his teaching job for a number of years.

In this case, which ought to be familiar to anyone who has cared for a person living with dementia, there are a number of unmet vital needs. First, Barry does not seem to be maintaining his personal hygiene, risking his skin integrity and leaving him vulnerable to infection (Baldelli et al. 2007, p. 45). Second, he does not seem to be managing his nutritional intake, leaving him vulnerable to foodborne illnesses. Third, he does not seem to be maintaining a safe environment, leaving him at severe risk of being harmed in a fire or by exposure to noxious gas. Fourth, he does not 
display emotional wellbeing, suggesting that he is struggling to self-soothe or otherwise manage his emotions.

Though only a doctor can diagnose Barry, there is more than adequate evidence here to suspect that he is living with dementia. If so, there are a number of reasons why Luke might believe his brother needs care. First, the condition impairs memory, co-ordination, spatial orientation, muscle memory and capacities related to cognitive processing and judgement, meaning he is unlikely to be able to tend to these unmet needs on his own (World Health Organization 2012, p. 7). Second, dementia is a progressive condition, meaning this impairment is likely to increase over time. Worse, many common symptoms of having unmet needs of this kind, such as dehydration and depression, may exacerbate this decline (Bennett and Thomas 2014, pp. 184-189). Finally, because Barry's subjective experience of the world seems to contain persistent misconceptions, he may not be able to recognise, interpret or express his needs to others.

These three features of dementia are vital to understanding why people who live with it are vulnerable to domination by malicious actors. Avoiding this, however, is not merely a matter of ensuring that their needs are met. On the contrary, if Luke were to hire carers who intervened directly in Barry's choices, they may expose him to power that does not track his interests, regardless of whether or not his vital needs are met.

To illustrate this, consider the following set of direct interventions. First, to ensure that Barry maintains adequate hygiene, his carer washes him and changes his clothes every morning. Second, to ensure that he maintains adequate nutrition, his carer takes over his shopping, cooking and monitoring his food supplies. Third, to ensure he maintains a safe environment, Barry's carer takes over the cleaning and organisation of his home. Fourth, to improve his emotional wellbeing, Barry's carer takes over any other task perceived to be causing him stress.

At first blush, such interventions might seem interest-tracking: especially if they were successful in attending to the unmet needs. After all, Barry almost certainly has an interest in being safe, well-fed and secure, all of which are likely to be fulfilled. However, there are a number of drawbacks to direct interventions of this kind that may frustrate other interests.

Firstly, such interventions may make it harder for a person living with dementia to make their wider interests known. If a carer were to provide Barry with personal care in a fast-paced way, for instance, his impaired evaluative capacities might be outpaced. Consequently, he may be unable to voice objections to the way he is being washed or suggest alternatives that better track his authentic values.

Further, if a carer were to make interventions in Barry's absence, such as shopping and cooking for him, he may not even have the opportunity to raise a concern. After all, because dementia impairs a person's memory and ability to weigh information, Barry may forget his objections or be unable to voice them without being prompted. Thus, he may end up eating meals that are cooked in ways he is not fond of or at times that do not suit him.

Secondly, because maintaining cognitive and physical activity has been shown to preserve functioning in people living with dementia, direct interventions may hasten the decline of their capacities (Cheng et al. 2014, pp. 63-74). Of course, cognitive 
decline itself is not, all things being equal, an unjust constraint. Indeed, it is widely thought that natural constraints which interfere with our interests are of a different kind than those imposed by others (List and Valentini 2016, p. 1070). However, if his decline were hastened by the actions of another who could have chosen otherwise, there would be a clear violation of Barry's avowal-ready interests. After all, he would not have chosen to become more dependent on others, yet he would have become so because of the actions of a powerful other.

Finally, because this unnecessary decline involves further impairment of their evaluative capacities, direct interventions may reduce a person's ability to evaluate their carer and the care relationship itself over time. After all, if his decline is hastened, Barry will have fewer opportunities to raise objections to non-interest tracking interventions and be less able to connect them to a broader understanding of how he relates to his carer. Thus, because he may forget the number of non-interest tracking interventions he has received from a particular carer, he may be less able to raise concerns to a third party or request a change in staffing.

Given these problems, a blanket policy allowing or requiring carers to make direct interventions without considering other options would be problematic. Of course, sometimes direct interventions may be the only option carers have to meet a person's needs. However, the risks involved suggest that people living with dementia, whatever the content of their wider interests, have a general interest in being empowered to meet their own needs, insofar as they can. Thus, where there are options that improve a person's ability to do so, direct intervention should not be a carer's first choice.

\section{Intervening Indirectly to Provide Cognitive Scaffolding}

In his current living situation, Barry appears unable to meet his own needs. That this is the case, however, does not necessarily entail that he needs care. After all, philosophers of disability have long disputed the excessive focus placed on a person's impairments as a cause of their disadvantage. Indeed, rather than through care, adherents to the social model of disability argue that unmet needs or disadvantages can be better addressed through societal reorganisation (Shakespeare 2006, p. 197). On this view, a lack of mobility, for example, might be addressed by changing the way public buildings are built or by making wheelchairs widely available (Shakespeare and Watson 1997, p. 296).

Though there have been some concerns about expanding the social model of disability to include cognitive disabilities (Wolff 2010, p. 151), there are valuable insights here for an analysis of dementia care. In fact, one need not even fully agree with the social model of disability, let alone expanding it to include cognitive disability, to recognise that there are a number of ways in which social reorganisation and improved access to assistive technology might prevent people like Barry from needing carers per se.

Regarding technology, there is profound potential to empower people living with dementia to meet their own needs. Dementia self-advocate Christine Bryden, for instance, has utilised assistive technology to write books, organise and give 
speeches at conferences, and produce a PhD thesis in theology (2018, pp. 27-41). Analogously, it is easy to imagine new artificial intelligence tools or Internet-enabled appliances being offered to Barry to help him to keep his fridges stocked, his gas turned off and his home clean. Were this technology to be made readily available, Barry and others like him may be prevented from needing an asymmetric care relationship.

Of course, some forms of this technology may be similarly disenabling; a smart fridge ordering Barry's food for him seems as direct an intervention as a carer buying it for him. However, if the purpose of the technology were to act as a prosthesis, responding to Barry's will rather than supplanting it, it would not carry this risk. What I am suggesting here, in other words, is that technology can sometimes be used as a form of what Andy Clark calls cognitive scaffolding: a term he used to describe the notes, labels and schedules he witnessed people living with dementia using to successfully maintain their independence, despite scoring poorly on cognitive tests (2003, pp. 139-140). Playing this role, it can hold information, be used to set reminders or otherwise externalise some of the cognitive functions Barry is losing, supporting his agency without the need for the care relationship.

Admittedly, such technology might be baffling or beyond Barry's control, which suggests that it may not always be appropriate. However, he may still be able to meet his needs with the assistance of non-technological forms of cognitive scaffolding to facilitate, maintain or improve his agency. For instance, his home environment could be reorganised such that he can see his clean clothes more easily or notes and signs could be used that prompt him to go shopping or check the gas switch on his oven. If this kind of environment shaping were enacted as an aim of public policy, perhaps pursued by outreach programmes, then it is likely that fewer people living with dementia would require asymmetric care relationships to meet their own needs.

It must be conceded, however, that social reorganisation of this kind is limited in scope. Indeed, while it may be relatively straightforward to reorganise the home of a person living with dementia, extending cognitive scaffolding into the shops, churches, parks and other public spaces in the wider community would be much more challenging. After all, what works as cognitive scaffolding for some might not work for others and, given roughly $7.1 \%$ of people over 65 live with dementia, there are likely to be a large number of people with conflicting demands, even in a very small town (Alzheimer's Society 2020).

This point should not be overstated; there are many changes that can be made in community centres to make them more accessible to people living with dementia. Indeed, through the dissemination of training programmes on how to deal with customers with dementia, the changes made to Purley High Street in the UK led to it being named a dementia-friendly community (Watts 2017), and similar movements exist in Japan (Alzheimer's Disease International 2020) and Belgium (Davies 2015). Nevertheless, insofar as they require access to the wider community to meet their needs, environmental organisation and assistive technology may only be able to prevent Barry and those like him from needing a care relationship in the early stages of the condition.

Regardless, the notion of cognitive scaffolding suggests that there are ways in which people living with dementia can be assisted to meet their own needs. While 
indirect interventions of this kind may not remove the need for carers in all or even most cases, they may greatly reduce their power while greatly improving the ability of those like Barry to live according to their own authentic values. Where such scaffolding is available, carers may only be necessary to maintain it or to assist those living in appropriately designed homes to access the wider community. Thus, ensuring readily available technology and access to environmental reorganisation is vital to a non-dominating practise of dementia care.

\section{Indirect Intervention Through Interpretation}

Cognitive scaffolding may put people like Barry in the position to meet needs that are going unmet because of impairments to memory, spatial orientation or judgement. What is critical to the case of Barry, however, is his mistaken belief that he is still working. As I have discussed extensively in previous work, all people living with dementia eventually experience life through what I have termed a parallel subjectivity: an internally consistent, subjective experience of the world featuring persistent misconceptions (Author, date reference to author's own work redacted). Thus, they may find it difficult to identify and express their own needs in a way that is comprehensible to the rest of us. Spatial reorganisation and technology may ameliorate some of this, but meeting the needs of someone with persistent misaligned beliefs will, inevitably, involve some level of interpretation.

Dementia studies pioneer Tom Kitwood makes a persuasive case that statements grounded in such misconceptions are attempts to communicate real needs (2019b, pp. 69-71). For instance, Barry's claim about his non-existent working life might reflect a feeling of being overwhelmed or a lack of control. Where people living with dementia are experiencing hallucinations and delusions in this way, vital needs may go unmet if others fail to investigate the reasons why they are making these claims. Moreover, even where the need is identified, it may go unmet if the carer cannot address it in a way that is explicable from the point of view of a person living with dementia.

On the other hand, as Kitwood notes, the apparent delusion or hallucination itself might reflect a misunderstanding the person living with dementia has about what we require from them, which arises from their need to interact with their environment in a meaningful way (2019a, pp. 88-91). Barry might believe he is still required to work because he has misinterpreted an aspect of his environment and it has acted as a trigger for earlier memories of his working life. Thus, one way in which his 'job' may have become 'tiresome' is that the objective world does not match his interpretation of how he ought to interact with it. For example, he might be trying to teach children on the television who do not appear to him to be listening, or he might be trying to mark books or newspapers that he interprets as homework.

A final consideration that ought to be noted is that Barry may not actually think he is still at work. Bryden encourages us to recognise the degeneration of language capacities that accompanies dementia, which may lead to people expressing themselves awkwardly or in a way that indicates a delusion that is not actually present 
(Bryden 2005, pp. 138-139). Understood this way, Barry's claim that his 'job' has become tiresome, may just be an awkwardly phrased way of explaining that his dayto-day routine has become difficult to manage.

To put Barry in a position to meet his own needs, then, a carer must be able to identify what is being expressed and interpret the world for him in a way that is comprehensible. In this way, the carer can act as an interpretive bridge between Barry's parallel subjectivity and the objective world, using this to inform their interventions.

For instance, if his belief that he is still working is a true delusion or hallucination, then a carer attending to that need may be able to organise his environment in a way that coheres with it; for instance, they might install a bell to signal the end of class and the beginning of a mealtime. Alternatively, if this is about a misunderstanding of what is needed of him, the carer may be able to direct him towards the tasks that are necessary to meet his own needs. For instance, the carer might say that they need to cook a meal or go shopping for food together to make sure that he is well enough to teach properly. If it is a communication impairment, on the other hand, the carer can indicate to Barry that they understand what he is trying to say and discuss with him how to ensure his needs are met.

No doubt, indirect intervention through providing cognitive scaffolding and interpreting parallel subjectivities may not be enough to meet all of the needs of a person living with dementia. However, because it avoids the pitfalls of reducing opportunities for objection, hastening the decline of capacities, and reducing the ability of people living with dementia to evaluate their care relationships over time, it is better placed to track their interests.

\section{Deception, Paternalism and the Domination of Carers}

Given the risks involved in direct intervention, I have argued that people living with dementia have an interest in being empowered to meet their own needs, wherever possible. In order to track this interest, carers should adopt an indirect-first approach to dementia care, wherein they refrain from direct intervention unless the person they are caring for cannot be empowered to meet their own needs through cognitive scaffolding or interpretation of their parallel subjectivity. Note, however, that this is not sufficient to liberate people living with dementia from domination, because they may still do so with impunity. In other words, it is not enough that carers choose to refrain from interventions that do not track the interests of those they care for; they must be prevented from doing so by being subject to oversight and robust laws (Pettit 2008, pp. 120-124).

The requirement to establish such an oversight regime, however, runs into the concerns highlighted at the outset by theorists of care. Marilyn Friedman, for instance, argues that this conception unacceptably renders the relationship between mother and child an archetypal relationship of domination (2008, p. 254). After all, a mother, like any carer, has a significant degree of authority over the person they care for, and makes a multitude of decisions which can frustrate their interests. 
Instead, she suggests, domination ought only to focus on actual attempts to interfere arbitrarily (pp. 250-252), a thought which is echoed by Kittay (1999, pp. 33-34).

While this may be attractive for those who would never dream of harming the people they care for, it brings with it disadvantages outside of the context of care. On a general level, it seems to suggest that there is nothing troubling, whether we call it domination or not, about relationships in which a person maintains an unexercised capacity to make non-interest tracking interventions. For example, M. Victoria Costa notes that failing to take into account this capacity, even when not exercised, makes an account of domination incapable of accounting for the injustices faced by women who 'preempt attempts at interference by seduction, ingratiation, avoidance, or other such strategies' (2013, p. 926).

Nevertheless, there is something compelling at the core of Friedman's argument. Given the power carers have over their charges, she argues that if its definition includes mere capacity, domination is ubiquitous and the only laws that could restrain it would be those that produce a police state. Much care, after all, goes on in private and so cannot easily be regulated from the outside. Given this, she argues, attempting to solve the domination of mothers over children would involve such a great expansion of state power that all carers would come to be dominated by state agents (Friedman 2008, p. 252). Thus, the implication here is that the conception of domination used by neorepublicans and most relational egalitarians presents an irresolvable problem; either care users are subjected to this power by their carers or their carers are subjected to this power by the state.

Though striking, there are, however, good reasons to doubt Friedman's analysis. For one, the idea that laws can and should restrain the power of carers to intervene with those they care for is intuitive; it is fairly standard for a country to have legal standards on child abuse, elder abuse and gross misconduct in professional caring roles. Admittedly, preventing carer domination would likely involve strengthening, further regulating and increasing oversight to ensure compliance with these laws, but it is not clear how this amounts to state domination. After all, presumably any society concerned enough about arbitrary power to monitor care relationships for non-interest tracking interventions would also monitor the monitors.

Perhaps from the perspective of the carer who would never dream of harming the person they care for, this is an unacceptable breach of their privacy and represents a demeaning judgement of their character but, given all carers would be subject to the same level of monitoring, it is unclear that this feeling arises from injustice. Perhaps, because a lot of care in the Western world is provided by women and members of ethnic minorities, there may be a concern of stigma but, again, the justification for this monitoring is grounded in the dangers of the relationship, rather than a judgement about those commonly occupying the more powerful position. Thus, though a carer may feel like they are being treated as if they would harm someone they care for, they would be being treated as such because of an accurate assessment of the professional or family position they occupy, not the social group of which they are a member.

Analogously, in many Western societies the majority of teachers of young children are women. Nevertheless, it is widely accepted that a just society should subject all prospective schoolteachers to extensive criminal record checks and monitoring 
by safeguarding teams, even those who would never dream of harming children. Thus, it is unclear how teachers and carers differ in this regard; if the personal is the political, as one of the key tenets of feminist theory states, then this surely applies to the relationship between carer and charge as much as it does the relationships between men and women in heterosexual couples.

Further, it is unclear that oversight requires constant monitoring of the activities of carers. Children have various contact points through which abuse can be detected and reported, such as play-groups, schools and outside clubs. Similar contact points might be established for other dependants, such that they too can be protected from interventions which do not track their interests. It might be the case that preventing domination requires rendering some care choices, such as home-schooling or eschewing professional contact with elderly relatives unjust, but it is unclear that this requires a state that is much more interventionist than that which is familiar to us.

Admittedly, as Anca Gheaus argues, parents are capable of arbitrarily intervening with their children's interests in numerous, seemingly trivial ways (2020), and the same might be true of other carers of dependants. Accordingly, we might think that it is highly inappropriate or disproportionate to level heavy sanctions when this occurs. Indeed, we might think a regime that is this punitive genuinely does dominate carers.

However, sanctions for such interference need not be heavy to be effective. If a carer frustrates their charge's interest in a trivial way, then a well-known, relatively trivial sanction may be appropriate. For example, we might establish a norm that a parent must offer an explanation for their actions, admit wrongdoing and reaffirm their love for their child if they lose their temper or react unfairly to their children. Likewise, in the case of dementia, we might establish a social norm that carers must attend additional training or give an account of their actions to a superior if they needlessly disrupt the agency of those for whom they are caring.

Of course, such norms cannot be rigorously enforced on every occasion but, through the contact points I mentioned above, it should become apparent to external actors when carers are not fulfilling their duties. As long as those bodies are empowered to intervene, either by reaffirming the duties a carer has or by offering support to ensure those duties can be met, there is a sufficient level of oversight to ensure they do not make non-interest tracking interventions with impunity.

\section{Conclusion}

In this paper, I have set out the view that dementia care can be non-dominating, if an indirect-first approached is pursued. Thus, relational egalitarians can include people living with dementia in the scope of justice without needing to jettison the neorepublican conception of domination.

Needless to say, in most jurisdictions the infrastructure, training and laws necessary to achieve this are not in place. Indeed, establishing such an effective regime will require significant social reform, with implications for all institutions which 
deal with people living with dementia. Nevertheless, to achieve just care relationships for members of this group, reforms with this goal in mind must be pursued.

Funding There is no funding necessary to declare attached to this article: it is my own work.

\section{Declarations}

Conflict of interest I declare that I have no conflict of interest regarding this work.

Consent for publish I consent to its publication should it be accepted.

Informed Consent I also note that there is no empirical data attached to this article that would require informed consent or data protection statements.

Open Access This article is licensed under a Creative Commons Attribution 4.0 International License, which permits use, sharing, adaptation, distribution and reproduction in any medium or format, as long as you give appropriate credit to the original author(s) and the source, provide a link to the Creative Commons licence, and indicate if changes were made. The images or other third party material in this article are included in the article's Creative Commons licence, unless indicated otherwise in a credit line to the material. If material is not included in the article's Creative Commons licence and your intended use is not permitted by statutory regulation or exceeds the permitted use, you will need to obtain permission directly from the copyright holder. To view a copy of this licence, visit http://creativecommons.org/licen ses/by/4.0/.

\section{References}

Alzheimer's Disease International. 'Japan-Dementia Friendly Communities'. Alzheimer's Disease International. Accessed August 6, 2020. https:/www.alz.co.uk/dementia-friendly-communities/ japan.

Alzheimer's Society. 'Dementia UK Report'. Alzheimer's Society. Accessed August 6, 2020. https:// www.alzheimers.org.uk/about-us/policy-and-influencing/dementia-uk-report.

Baldelli, M. V., R. Boiardi, P. Ferrari, S. Bianchi, and M.H. Bianchi. 2007. Dementia and occupational therapy. Archives of Gerontology and Geriatrics 44: 45-48.

Bennett, Sophia, and Alan J. Thomas. 2014. Depression and dementia: Cause, consequence or coincidence? Maturitas 79 (2): 184-190.

Bryden, Christine. 2005. Dancing with dementia: My story of living positively with dementia. London: Jessica Kingsley Publishers.

Bryden, Christine. 2018. Will I still be me?: Finding a continuing sense of self in the lived experience of dementia. London: Jessica Kingsley Publishers.

Bubeck, Diemut E. 1995. Care, gender, and justice. Oxford: Oxford University Press.

Cheng, Sheung-Tak., Pizza K. Chow, You-Qiang. Song, Edwin C. Yu, Alfred C. Chan, Tatia M. Lee, and John H. Lam. 2014. Mental and physical activities delay cognitive decline in older persons with dementia. The American Journal of Geriatric Psychiatry 22 (1): 63-74.

Clark, Andy. 2003. Natural-born cyborgs: Minds, technologies, and the future of human intelligence. Oxford: Oxford University Press.

Costa, M. Victoria. 2013. Is neo-republicanism bad for women? Hypatia 28 (4): 921-936.

Davies, Ross. 2015. 'Is Bruges the most dementia-friendly city?' The Guardian. Last modified April 21, 2015. https://www.theguardian.com/society/2015/apr/21/bruges-most-dementia-friendly-city.

Friedman, Marilyn. 2008. Pettit's civic republicanism and male domination. In Republicanism and political theory, ed. Cecile Laborde and John Maynor, 246-268. Malden, MA: Blackwell Publishing. 
Gheaus, Anca. 2020. Child-rearing with minimal domination: A republican account. Political Studies 69: $748-766$.

Held, Virginia. 2006. The ethics of care: Personal, political, and global. Oxford: Oxford University Press.

Kittay, Eva F., and Love's Labor. 1999. Essays on women, equality, and dependency. London: Psychology Press.

Kitwood, Tom. 2019a. The experience of dementia. In Dementia reconsidered, revisited: The person still comes first, ed. Dawn Brooker, 83-96. London: Open University Press.

Kitwood, Tom. 2019b. Personhood maintained. In Dementia reconsidered, revisited: The person still comes first, ed. Dawn Brooker, 64-77. London: Open University Press.

List, Christian, and Laura Valentini. 2016. Freedom as independence. Ethics 126 (4): 1043-1074.

Nath, Rekha. 2020. Relational egalitarianism. Philosophy Compass 15 (7): e12686.

Pettit, Phillip. 2008. Republican freedom: Three axioms, four theorems. In Republicanism and political theory, ed. Cecile Laborde and John Maynor, 102-130. Oxford: Blackwells.

Pettit, Philip. 2006. The determinacy of republican policy: A reply to McMahon. Philosophy and Public Affairs 34 (3): 275-283.

Shakespeare, Tom. 2006. The social model of disability. In The disability studies reader, ed. Lennard J. Davis, 197-205. Oxford: Taylor \& Francis.

Shakespeare, Tom, and Nicholas Watson. 1997. Defending the social model. Disability and Society 12 (2): 293-300.

Tronto, Joan C., and Moral Boundaries. 1993. A political argument for an ethic of care. London: Psychology Press.

Watts, Peter. 'Forget-me-nots in Purley: How the town became "dementia friendly"'. The Guardian. Last modified February 2, 2017. https://www.theguardian.com/cities/2017/feb/02/purley-uk-latest-demen tia-friendly-community.

Wolff, Jonathan. 2010. Cognitive disability in a society of equals. In Cognitive disability and its challenge to moral philosophy, ed. Eva F. Kittay and Licia Carlson, 147-158. Chichester, UK: John Wiley \& Sons.

World Health Organisation. 2012. Dementia: A public health priority. World Health Organisation.

Publisher's Note Springer Nature remains neutral with regard to jurisdictional claims in published maps and institutional affiliations. 